\title{
El Proyecto de Arqueología Urbana '93: Un instrumento de conocimiento e interven- ción para la ciudad de Jaén
}

\author{
Ma Carmen Pérez* \\ Francisca Hornos** \\ Eva Ma Alcázar****
}

Nuestra intención en este artículo es presentar las reflexiones que, sobre la propuesta metodológica diseñada para la investigación arqueológica en cascos urbanos hemos desarrollado hasta la fecha, configurándose en torno al Proyecto "Estudio Arqueológico del Casco Urbano de Jaén" desde 1993, del cual una de nosotras es la directora (MCPM).

\section{ANTECEDENTES: EL PROYECTO URBANO INFORMAL.}

Para entender los objetivos y metodología que nos planteamos en el Proyecto, hemos de dar un paso atrás y hacer memoria de la dinámica que la arqueología urbana ha seguido en nuestra ciudad.

Ya desde principios de siglo, en revistas de ámbito provincial como DON LOPE DE SOSA, y posteriormente en PAISAJE y en el Boletín del Instituto de Estudios Giennenses, se pueden rastrear un buen número de descripciones de hallazgos arqueológicos casuales, en las que se deja entrever una concepción positivista de la arqueología; se partía del presupuesto que tendía a identificar el bien arqueológico con el objeto (ya fuera éste una estructura o un bien mueble), y no con el contexto: lo importante era recuperar y extraer el bien (si era mueble) o bien la tutela de su integridad (si era inmueble), y no la salvaguardia y la documentación del conjunto, es decir, de todos los componentes culturales y naturales que forman el depósito arqueológico.
El despegue de la investigación arqueológica en Jaén, está ligado al desarrollo de las investigaciones del Departamento de Prehistoria del antiguo Colegio Universitario (1978), sin embargo todos los proyectos dirigidos desde este ámbito se han desarrollado en zonas rurales, teniendo como objeto de estudio el territorio en diferentes fases culturales pero sin incluir a la ciudad como zona arqueológica pluriestratificada y aún viva.

Al igual que en la mayoría de las provincias andaluzas, 1986 fue el año en que "nace" la arqueología urbana en Jaén. Desde este año, la metodología de las excavaciones de urgencia -principal recurso de la arqueología urbana-, ha sufrido una evolución, superándose esa concepción reduccionista de lo que debía ser una excavación en ambientes urbanos. Los investigadores adoptarán los métodos usados en las excavaciones realizadas en sitios arqueológicos que fueron abandonados o decayeron en un momento de su historia, es decir, la excavación por cortes estratigráficos, en la que se hacen sondeos de tamaño limitado por toda la zona arqueológica para documentar los estratos que se han ido depositando a lo largo de la ocupación humana del lugar, o bien la excavación extensiva, en la que toda la zona arqueológica es excavada. Un nuevo paso, será la adopción por parte de la arqueología de la ciudad del método de análisis estratigráfico o método Harris (HARRIS, 199I), que unifica los dos anteriores.

* Directora del Proyecto "Estudio Arqueológico del Casco Urbano de Jaén"

*** Conservadora del Patrimonio Histórico

****Miembro del Depto. de Territorio y Patrimonio, Área de Historia Medieval. Universidad de Jaén 
La primera intervención propiamente urbana se realizó en 1986, en el edificio que ocupaba el antiguo Grupo Escolar de "Los Caños de S. Pedro" en pleno casco histórico de Jaén. Las obras de restauración del inmueble, sacaron a la luz restos arqueológicos cuya magnitud motivó que la Consejería de Cultura financiase una excavación "de apoyo a la restauración" que documentó un baño árabe datado a mediados del S. XI y que fue ampliamente reutilizado en períodos posteriores como tahona, pescadería, carnicería y ya en época contemporánea como Grupo Escolar. El edificio se encuentra actualmente en proceso de rehabilitación para uso público. Del baño sólo se consolidarán las trazas que de él restan en uno de sus muros, así como dos habitaciones del tepidarium que se conservan íntegramente. No nos extenderemos en su descripción ya que en 1993 se publicó una monografía con los resultados de las tres campañas (VV.AA., 1993).

Desde estos momentos y en progresión ascendente podemos contabilizar más de ochenta intervenciones (excavaciones de urgencia, de apoyo a la restauración, seguimientos, etc.) hasta nuestros días. Sin embargo, sólo ha sido analizada la información proporcionada por aquellas de secuencia más compleja -apenas una decena-.

La excavación en la IGLESIA DE S. JUAN, se realizó en 1989 como paso previo a la restauración de la misma. En las criptas se localizó parte de una vivienda musulmana con una cronología que abarca desde el $\mathrm{S}$. Xl a mediados del S. XIII. Se observaban claramente tres fases de construcción, perfectamente selladas por sus correspondientes pavimentos, lo que la convierte en la mejor estratigrafía de época musulmana hallada hasta el momento, al no haber sido alterada por construcciones posteriores a excepción de los paramentos de la Iglesia. La dirección de los muros de esta vivienda y el cálculo de la extensión que podía tener la misma, hacía pensar que ésta ocuparía parte de la calle Martínez Molina. En tal caso, la antigua concepción, mantenida por diversos autores, de una ciudad estructurada en base al antiguo cardo y decumano romano (identificados como las actuales calles de Martínez
Molina y Almendros Aguilar) y que aún conservaba una configuración urbana heredada del período islámico quedó en entredicho: más bien, la ciudad que hoy observamos es fruto de las profundas remodelaciones iniciadas en el período medieval cristiano por el Condestable Miguel Lucas de Iranzo (CASTILLO, CASTILLO, |989-199|).

A lo largo de 199| se realizaron dos intervenciones emblemáticas tanto por su magnitud como por los resultados que aportaron para el conocimiento histórico.

La primera de ellas ocupaba un gran solar delimitado por las calles Millán de Priego, Rey D. Pedro, Hornos Franco y S. Andrés. Fue de inicios bastante conflictivos, al ser destruido durante los trabajos de demolición un lienzo de la muralla musulmana que cerraba el solar en su lado norte, conservándose aún una torre embutida en las viviendas. Esta polémica derivaría en la ampliación del Conjunto Histórico.

La secuencia histórica documentada fue muy amplia. Por el solar discurría uno de los antiguos arroyos que partían del manantial de la Magdalena documentándose materiales de arrastre desde la Edad del Bronce hasta el período romano. El encauzamiento del mismo se realizó en el S. XII al urbanizarse la zona construyendo varias viviendas, algunas de ellas casi pegadas a la muralla, lo que es un índice claro del proceso de macización que debió sufrir la ciudad en este siglo (SALVATIERRA et alii, 1993). Tras la conquista cristiana de la ciudad, desde mediados del S. XIII hasta el S. XV, se reutilizaron la mayor parte de las estructuras musulmanas adaptándolas a las necesidades de la nueva población. Ya en época moderna, la zona sufre un fuerte proceso de construcción al edificarse viviendas de gran envergadura, así como un molino de pan, del que se tienen referencias también en las fuentes escritas. Por último en época contemporánea el solar mantiene la función industrial adquirida en el período anterior, con la construcción de un molino de aceite a partir del S. XVIII, que se mantendrá en funcionamiento hasta bien entrado el S. XX. (CASTILLO et alii, 1992). 
Al igual que la anterior, la intervención que denominamos como BAÑOS DE LA AUDIENCIA, se realizó en una gran manzana delimitada por las calles Martínez Molina, Baños de la Audiencia, Doctor García Anguita y Corregidores. El origen de la ocupación del solar se sitúa en el período Ibérico Tardío, siendo la primera vez que en la ciudad se documentaba un importante conjunto de materiales asociados a estructuras pertenecientes a esta fase, lo que indica la existencia de un segundo núcleo de población, ya que hasta ese momento tan sólo se habían recuperado materiales de arrastre o caidas, procedentes de un asentamiento situado en la ladera del Cerro Sta. Catalina. El solar no volverá a ocuparse hasta el S. XII con la construcción de dos viviendas musulmanas, muy modificadas por edificaciones de épocas posteriores. Este amplio hiatus cronológico, nos permite esbozar el ritmo y tendencia de crecimiento que sufrió la ciudad islámica, que culminaría con la construcción de una nueva mezquita aljama por los almohades, en el lugar donde hoy se asienta la Iglesia Catedral. A partir del S. XV, y sobre todo en época moderna, la zona se convertiría en uno de los centros más importantes de la ciudad al construirse un buen número de edificios públicos, concretamente en el solar, se ubicaría la antigua Casa de Corregidores (IIMÉNEZ y CHICA, en prensa).

Durante 1992, en la C/ Martínez Molina, esquina C/ Los Caños, justo por encima del Baño Árabe del Naranjo y muy cercana a la Iglesia de S. Juan, se documentaron los cimientos del alminar de una mezquita, con toda probabilidad construida a finales del S. XI, y que estaría casi adosada a los Baños conformando así el binomio Baño-Mezquita en la más pura tradición islámica (PÉREZ y JIMÉNEZ, en prensa; PÉREZ y ALCAZAR, 1993; PÉREZ et alii, en este mismo volumen).

En un pequeño solar de la C/ Borja, en 1993 se documentó un tramo de la muralla romana que según el responsable de la excavación debe fecharse a finales del S. I d.C. Su utilización con fines defensivos fue muy corta ya que en el siglo II de Nuestra Era, la muralla se convierte en un vertedero y no vuelve a ocuparse hasta finales del S. XI con la construcción de la muralla islámica a escasos metros de ésta (ZAFRA, en prensa). A partir de los datos recogidos en esta intervención, se ha realizado un diseño aproximado de los límites de la ciudad romana.

Durante 1994, en la C/ Las Huertas, a escasos metros de la línea de muralla musulmana se localizaron los restos de una vivienda islámica con una amplia cronología que va desde finales del S. XI hasta mediados del S. XIII (ZAFRA y CANO, en prensa).

Por último, en el mes de octubre de 1994, se finalizó una intervención de apoyo a la restauración en el llamado Palacio de los Uribes, donde hipotéticamente se encontraba el Palacio del gobernador árabe. Aún no podemos adelantar ningún resultado ya que la magnitud de los restos arqueológicos documentados ha hecho necesario la petición de una segunda fase. No obstante hay que destacar el qanat localizado en su interior, en perfectas condiciones y con varias ramificaciones, del que se ha podido recorrer unos $130 \mathrm{~m}$. aproximadamente (CANO, en prensa).

Gracias al análisis de los datos aportados por estas intervenciones, se ha avanzado de forma considerable en el conocimiento histórico de la ciudad. Hoy estamos en condiciones de proponer un modelo de la evolución urbana de Jaén: la etapa iberorromana, con menos evidencias que la medieval, empieza a ser interpretada de una forma global. En el período medieval se han documentado las transformaciones que sufrió la ciudad, tanto en época musulmana en las fases correspondientes a los siglos XI - XIII -aunque aún no se han contrastado datos suficientes para los siglos VIII - X-, como en los primeros siglos de dominación cristiana (SALVATIERRA, 1993). En cuanto a la ciudad moderna y contemporánea, a pesar de los numerosos datos localizados en la mayoría de las intervenciones, aún queda por hacer una interpretación arqueológica de los mismos que conecte con los modelos de evolución propuestos por las síntesis escritas desde la perspectiva documental (ULIERTE, 1990) (LAZARO, 1986). 
Sin embargo, durante estos ocho años de trabajo arqueológico, se ha acumulado mucha más información de la que ha sido utilizada. Hoy contamos con un importante volumen de datos, planimetrías, y material tanto cerámico como fotográfico que llena nuestros almacenes y archivos, la mayor parte de ellos sólo parcialmente estudiados y que se incrementan progresivamente debido a la dinámica propia de la arqueología urbana.

Esta información debía ser sistematizada y estructurada siguiendo criterios metodológicos que la hicieran útil y gestionable: el disponer de un sistema de registro y catalogación arqueológico homogéneo se había convertido en un imperativo para todos los sectores implicados en el Sistema Urbano: historiadores (especializados en documentación escrita $\circ$ en cultura material), Administración Pública y sector privado.

Esta situación, es decir el análisis de la misma, donde las interpretaciones han sido "cómodamente" sesgadas en fases culturales, donde la realidad compleja del registro arqueológico actual, que evidencia lo contemporáneo por encima de todo choca con lo anterior, fue lo que nos hizo ver la necesidad de diseñar una nueva forma de "intervenir para conocer" la ciudad.

\section{EL PROYECTO DE ARQUEOLOGIA URBANA '93: DESDE EL PROTOTIPO "SOLARES" HASTA LA ACTUALIDAD.}

Esta situación nos llevo a las autoras de este artículo a iniciar, a comienzos de 1993, la complicada empresa de configurar un Modelo de Registro Arqueológico, cuyo objetivo era el de inventariar, almacenar y registrar todos los datos posibles sobre el pasado histórico de la ciudad.

El instrumento que nos daba la posibilidad de estructurar, gestionar y analizar la información en plazos breves, era la Informática. El desarrollo de una estructura informática abierta, que permitiera la construcción de un registro de toda la información recabada, para su posterior manejo y análisis era fundamental, sobre todo porque permitía, a través de unos lenguajes que se están estandarizando, el acceso de todas las partes interesadas, a una información con la cual tendrán que contar cuando se trate de realizar proyectos de construcción o planificación urbana, y de diseñar nuevas estrategias en la tutela del Patrimonio Histórico Urbano y en la investigación histórica.

\section{Estructura y potencia informativa.}

Este tratamiento informático nos exigía que en el proceso de introducción de datos hiciéramos un esfuerzo para traducir nuestro sistema de registro habitual, eminentemente descriptivo- narrativo, a un lenguaje que fuera aceptado por la estructura lógica del ordenador cuya exigencias son la concisión y la especificidad.

Es decir, debíamos diseñar un registro que a la vez nos sirviera como matriz de una Base de Datos cuyos objetivos fundamentales fuesen:

- Cuantificación de la potencialidad del Patrimonio Arqueológico-Arquitectónico de forma global, zonal y por fases cronológicas, para generar a partir de ella Cartas Arqueológicas que reconstruyan diacrónicamente la fisonomía del centro habitado en su desarrollo topográfico y funcional, analizando no sólo los niveles estratigráficos horizontales, sino también los resultados de una lectura estratigráfica de las estructuras arquitectónicas emergentes. De esta forma, la Base de Datos habría de contener información sobre las reestructuraciones, restauraciones o rehabilitaciones de cada inmueble, así como su uso actual y los anteriores conocidos.

- Detección de las zonas más afectadas o que entran dentro de una Escala de Riesgo, diseñada teniendo en cuenta la incidencia de los factores de degradación y el valor de los restos amenazados.

- Medición de los factores de degradación o alteración, considerados en su integración dinámica y en sus distintas incidencias, respecto a las variantes tipológicas o cronológicas del Patrimonio a salvaguardar. 
- Constatación de la esterilidad arqueológica de determinadas zonas.

- Cuantificación de la pérdida de información arqueológica producida por las intervenciones en el subsuelo documentadas hasta la fecha.

Todo ello nos permitiría evaluar el estado de la información arqueológica en la ciudad y realizar estrategias de intervención que permitiesen rentabilizar los trabajos arqueológicos.

\section{Primera fase de elaboración.}

Ante la magnitud del proyecto, se planteó la realización de un prototipo experimental seleccionando cuatro calles y cuatro plazas de la ciudad. Para la selección de éstas se tuvo en cuenta la disparidad de factores que podríamos encontrar, por ejemplo, diversos estados de conservación de los edificios, diferente potencialidad arqueológica, diferente grado de destrucción o sustitución, existencia de edificios catalogados B.I.C., etc. Todo ello nos abriría un amplio abanico de situaciones en las que ensayar nuestro modelo para que fuese lo más flexible y versátil posible.

El primer problema a resolver era definir la unidad espacial básica a partir de la cual se estructuraría la información.

La parcela catastral nos pareció la más adecuada, en primer lugar porque es la que se utiliza a efectos de planificación urbana, siendo la más familiar, tanto para las distintas administraciones, como para los profesionales que ejecutan las sustituciones arquitectónicas, constituyendo además la superficie habitual de intervención arqueológica en la ciudad, a partir de la cual se trazan las planimetrías de los restos arqueológicos hallados. En nuestro prototipo se contabilizaron un total de 240 solares, construidos o no.

Una vez determinada la unidad espacial de aplicación, el trabajo se organizó en diversas fases.

\section{La información documental.}

Recopilación de las noticias que aparecen en la documentación escrita sobre el urbanismo de la zona de estudio, a lo largo de su historia, tanto en lo que se refiere a las obras públicas como a la edilicia privada.

El trabajo se inició en el archivo del Ayuntamiento de Jaén. La consulta de las Actas Capitulares nos permitió conocer el momento de apertura de las calles, realizando así un seguimiento de la expansión urbana de la ciudad en los distintos períodos históricos. Las Licencias de Obras Mayores concedidas por el Ayuntamiento, se revelaron como uno de los documentos más interesantes, ya que en ellos se especifica la fecha de construcción de los inmuebles, la destrucción de originales, el tipo de edificación, el uso a que se destina, el arquitecto responsable y la existencia en las nuevas construcciones de elementos que hayan podido destruir la potencialidad arqueológica como sótanos, aparcamientos, etc. A través de las licencias de Obras menores se han podido documentar las modificaciones realizadas en edificios singulares a lo largo del tiempo, lo que facilitaba enormemente los estudios de estratigrafía muraria.

Esto se completó con la consulta de los Expedientes de la Comisión Provincial de Patrimonio Histórico, referentes a todos los proyectos de sustitución de inmuebles en el casco histórico, que se ejecutan en la actualidad.

Otra de las fuentes interesantes, consultada en el Archivo Histórico Provincial, es el Catastro de Ensenada, confeccionado a mediados del S. XVIII, momento en el que aún se conservaba un buen número de edificios históricos hoy desaparecidos (muralla, conventos, acueductos, termas, iglesias, casas señoriales, etc.) y se mantenía casi invariada la estructura heredada del período medieval cristiano. En la descripción que realiza de los inmuebles se indica concienzudamente la existencia de bodegas, sótanos o pozos, lo que nos permitió evaluar la potencialidad arqueológica de las calles. Igualmente se podría reconstruir la topografía de la ciudad, los espacios habitados y deshabitados, etc. 
Junto a ello, realizamos una búsqueda sistemática de revistas, periódicos y libros especializados que se interesaran por temas de arqueología y arquitectura, para recabar noticias sobre posibles hallazgos arqueológicos, así como para conocer más sobre la historia y la evolución de los edificios más señeros y para documentarnos sobre los tipos de construcción tradicionales.

La búsqueda de antiguas planimetrías de la ciudad y colecciones de fotografías antiguas fue bastante útil para situar con cierta precisión en la cartografía moderna edificios, calles y plazas, de los que sólo perviven referencias escritas, o bien para la identificación de restos arqueológicos.

\section{Los documentos materiales (información arqueológica). El modelo de registro.}

La labor de archivo se ha complementado con la realización de unas prospecciones sistemáticas por las calles seleccionadas, inventariando cada uno de los edificios que las delimitan y cotejando todas las noticias recogidas en archivo con la realidad. Para ello se diseñó una Ficha de Campo (f. I-2) aplicada a cada parcela catastral, que contemplaba los siguientes campos de información:

- Documentación fotográfica y cartográfica.

- Identificación administrativa.

- Datación relativa.

- Evaluación de su estado actual y control de su grado de conservación.

- Constatación de elementos que alteren el substrato arqueológico.

- Lectura estratigráfica superficial de los paramentos.

- Comprobación de la existencia de documentación arqueológica e histórica.

Uno de los objetivos más importantes y que se reveló como la tarea más complicada, fue la realización de la Ficha de Información Arqueológica, ya que son numerosísimas las intervenciones arqueológicas realizadas, con criterios metodológicos dispares y distintas estrategias de intervención dependiendo de cada profesional; la situación se agrava aún más porque las intervenciones arqueológicas en áreas urbanas deben adaptarse a la típica fragmentación en pequeños solares, que dificultan sobre manera el intento de un registro sistemático y globalizador, que a la vez no menoscabe calidad y riqueza de la información.

En definitiva, debíamos tener en cuenta que en cada intervención arqueológica nos enfrentamos con una casuística que no tiene nada de homogénea ni de sistemática, y que no ofrece, en el $95 \%$ de los casos, una interpretación fácil, muchas veces por fragmentaria: desde la esterilidad arqueológica del terreno por no haber sido habitado hasta el presente siglo o bien por la destrucción de cualquier rastro de estratigrafía por fosas de cimentación recientes, al aprovechamiento en edad moderna y contemporánea de estructuras medievales que descansan a su vez en niveles iberorromanos, son innumerables las situaciones que la arqueóloga o arqueólogo encuentra y ante las cuales debe reaccionar según su criterio.

Por otro lado, después de realizar el trabajo y dar un diagnóstico, el único canal de difusión de los datos obtenidos es en general un informe escueto, que no contiene la suficiente información para cumplimentar debidamente la ficha que hemos elaborado, por lo que tuvimos que recurrir a los diarios manuscritos de cada excavación, a las planimetrías, los registros, etc. la recopilación de todos estos documentos se convirtió en una dificultad añadida.

A nuestro juicio, cuando se trata de arqueología en la ciudad, entendiéndola como una zona arqueológica única, pluriestratificada, y por tanto de una magnitud muy superior a cualquier otra de un período determinado, la realización de una ficha extensa, cuya base sea la unidad sedimentaria (como la utilizada por el sistema ArquèoDATA, por ejemplo), podría resultar inoperante a la hora de gestionar y 
optimizar los resultados, e impracticable en la toma de datos de campo. Es decir, elaborar una Base de Datos con un volumen muy elevado de registros, provocaría una saturación del sistema y nos perderíamos en un mar de noticias entre las que sería difícil extraer una conclusión: piénsese que una intervención en un solar de $1000 \mathrm{~m} 2$, con un amplio horizonte cronológico, pueden documentarse de 500 a 1000 U.S.. En definitiva, "los árboles no dejarían ver el bosque". Por lo tanto, nuestra propuesta es utilizar la fase cronológica como unidad básica de información, pues pensamos que le da a la ficha la suficiente flexibilidad para aplicarla a las distintas situaciones con las que nos podemos enfrentar y permite que en ella se aprecie de forma clara la formación y dinámica histórica del solar y su evolución topográfica (f.3-4). Esquemáticamente se recogen los siguientes campos de información:

- Datos administrativos del solar y de la intervención.

- Datos topográficos.

- Detección y descripción de fases cronológicas, englobadas en grandes fases culturales.

- Caracterización de las distintas fases documentadas

Todo ello iría acompañado por archivos paralelos donde se introduciría la documentación de campo, planimétrica y fotográfica, así como el estudio de materiales.

Respecto a este último, y como ya apuntábamos antes, los ocho años de intervenciones urbanas han producido una ingente cantidad de materiales cerámicos, que colman los almacenes del Museo. La mayor parte de ellos no han recibido ningún tipo de tratamiento y mucho menos un estudio exhaustivo, a excepción de los fragmentos más significativos para su publicación en el Anuario Arqueológico. La situación no deja de ser problemática si pensamos que el paso del tiempo puede borrar cualquier huella identificativa en etiquetas y bolsas, provocando además un tremendo deterioro de materiales que necesitan un tratamiento específico como metales, vidrio, fauna, etc. Así pues, el gran esfuerzo realizado para documentar aquello que iba a desaparecer irremediablemente, puede resultar inútil si se pierde la información que guardamos en los almacenes. Por otro lado, esta pérdida de información es un grave condicionante para el desarrollo de la investigación sobre la ciudad y para planificaciones futuras.

Nuestra propuesta inicial de ficha de estudio de materiales, se ha completado con la realizada por $\mathrm{M}$. Castro y $\mathrm{C}$. Rísquez responsables del Proyecto "Catalogación de los fondos del Museo Arqueológico Provicial de Jaén" concedido en 1993.

La información se estructurará en función de una ficha básica de conjunto de materiales donde se refleje (f.5-6):

- Identificación del material a través de un código administrativo.

- Contextualización arqueológica del material.

- Localización topográfica en el Museo.

- Número de elementos por conjunto.

- Descripción formal del conjunto.

- Constatación de la necesidad de actuaciones de conservación-restauración.

- Adscripción cultural.

Los materiales de selección fueron dibujados y analizados con más detenimiento por lo que a la ficha de conjunto se le añadió una ficha más extensa aplicada a cada fragmento (f. 7).

\section{La representación cartográfica.}

Una fase importante de nuestro trabajo, es el de la representación de toda esta información sobre el Patrimonio Histórico de nuestra ciudad, en un soporte cartográfico adecuado. Nuestro objetivo era proporcionar un instrumento operativo que permitiera 
visualizar de forma sintética todos los datos recabados, a fin de que el acceso a éstos fuera sencillo e inmediato tanto para los investigadores, como para los sectores dedicados a la planificación urbana y a la programación de las intervenciones de tutela y de conservación.

Esta diversidad de usuarios nos llevó a excluir la tradicional representación simbólica, de implicación temática, útil sólo para los aspectos históricos y que ha sido, por ejemplo, la utilizada habitualmente para realizar las Cartas Arqueológicas: nos referimos a esas representaciones cartográficas, en las que, por ejemplo, a un parcelario realizado a escala de una ciudad, se le superponen símbolos gráficos -círculos, triangulos, etc., o bien tramaspara indicar la presencia de restos arqueológicos. Estos símbolos no respetan la escala del parcelario al que se adosan, y la información que dan es puramente orientativa.

Aspiramos a crear una cartografía arqueológica en la que las planimetrías antiguas que la investigación científica ha conseguido recomponer aparezcan junto a las que, a lo largo del tiempo, las han sustituido, destruido o modificado, hasta llegar a la actual, eliminando los símbolos que nos informaban sólo de la presencia de restos para representar la auténtica forma y tamaño de éstos.

Nuevamente eran las tecnologías informáticas el instrumento para lograrlo: La Cartografía Numérica, idónea en cuanto que proporciona una representación virtual, y por lo tanto no condicionada por el índice de escala, de cualquier situación o distribución espacial de la realidad. El proceso de elaboración consiste en que el ordenador construye el mapa a partir de varios "niveles" o capas de diseño electrónico, memorizados mediante la digitalización -es decir, la conversión en números- de las coordenadas de las denominadas "primitivas gráficas" -las líneas y puntos básicos que conforman cualquier entidad espacial- con las que se asocian, a través de las expresiones matemáticas que para el ordenador las representan, los elementos geométricos más complejos.
En la actualidad estamos ultimando la digitalización de nuestro parcelario, solar por solar, como soporte cartográfico básico para nuestra información. Posteriormente habrá que digitalizar en cada solar excavado las estructuras de épocas anteriores.

La necesidad de conjuntar en nuestro trabajo, por una parte, bases de datos alfanuméricas, a partir de las cuales generar nuevos datos, analizar procesos y desarrollar modelos para gestionar las informaciones referidas a la Ciudad y a su evolución con respecto a los fenómenos que le afectan, y por otra, producir una representación cartográfica de todo ello, uniforme, coherente y actualizada, será solventada con el uso de lo que se considera el vértice en la jerarquía de los soportes informáticos aplicados a la gestión territorial: Los Sistemas de Información Geográfica o Territorial (S.I.G.).

En ellos, la cartografía numérica se debe entender sólo como la referencia principal de un conjunto (o, como su propio nombre indica, Sistema) de bases de datos con tantos componentes como creamos necesarios, seleccionables en base a las exigencias de los usuarios finales (en nuestro caso serían datos administrativos, documentales, arqueológicos, topográficos, etc.), siendo su reproducción sólo uno de los posibles objetivos, formando además, todo el aparato de información, parte integrante del mapa virtual memorizado por el ordenador, denominándose Bases de Datos Georeferenciadas, es decir, información recogida de la realidad, que se sitúa espacialmente y que se representa a través de sus coordenadas geográficas.

El producto de todo ello será la construcción de un Sistema de Información Arqueológica de la Ciudad (f.8).

Efectivamente, el ámbito urbano representa un banco de pruebas ideal para la experimentación de estos sistemas: compacidad de las entidades físicas representadas, concentración de los problemas, existencia de bases cartográficas homogéneas (el parcelario, el catastro), enfrentamiento inmediato con posi- 
bilidades de interacción con el mundo de la planificación, y el aliciente de poder paliar los problemas derivados del impacto entre la realidad actual y la herencia del pasado (AZZENA y TASCIO, 1988; AZZENA, 1992).

Una de las consecuencias directas de la construcción de un Sistema de Información Arqueológica, es la posibilidad de fabricar a partir de los datos recabados, la Carta Arqueológica y la Carta de Riesgo. Ésta última se define como un instrumento que nos permite visualizar de forma rápida y global el estado actual del Patrimonio ArqueológicoArquitectónico de nuestra ciudad, siendo elaborada a partir de, en primer lugar, todas las informaciones de diversa índole que han sido recogidas sobre él (su importancia, consistencia, potencialidad, vulnerabilidad, etc.) y en segundo lugar, sobre los peligros que lo amenazan, permitiendo establecer entre estos dos conjuntos básicos de información temática "un sistema de correlaciones para determinar las concretas relaciones causales y de probabilidad que existen entre el Patrimonio de los Bienes Culturales arquitectónicos, arqueológicos e histórico-artísticos, su estado de conservación y los factores de peligrosidad que provocan su deterioro" (WV.AA., 1992, p. 12).

Qué duda cabe que estos instrumentos aumentan la rentabilidad y optimización de los recursos, tanto humanos como financieros, que se dedican al estudio y salvaguardia de nuestro Patrimonio, lo que a la larga permitirá paliar de alguna manera la conflictividad social que la arqueología urbana lleva implícita. Esta utilidad empieza a ser reconocida por la sociedad, lo que está permitiendo la elaboración de estos documentos con canales de financiación muy diversos.

\section{Estrategias de defensa y apropiación social:}

El conocimiento y la conservación del Patrimonio Histórico, en todos sus aspectos, se convierte en un tema de interés en aquellas sociedades que han alcanzado el grado suficiente de complejidad cultural y con una situación económica estable, para poder plantear la recuperación de la memoria del pasado.
Entendemos que la sociedad "interesada" es la población en la que se define este instrumento, en este caso la ciudad de Jaén, por esto es importante desde el principio que la investigación arqueológica en la ciudad sea conocida por los ciudadanos. De hecho, y tal como se ha formulado para una zona periférica de la ciudad de Sevilla, es bastante peligroso dejar en manos de otros lo que nos es propio como ciudadanos (CARMONA, 1994, p.29). Como historiadores, creernos los protagonistas del proceso, es cuanto menos, un ejercicio peligroso de ensimismamiento, que no produce una verdadera investigación histórica y que suele desembocar en tensiones que a menudo degeneran en conflicto.

Todo lo anterior nos lleva a plantear como prioritarios los objetivos de difusión dentro del Proyecto de Arqueología Urbana: desde el método, hasta los resultados. Nos referimos a publicaciones como ésta desde la que nos expresamos, pero también nos interesa, mediante el instrumento de la encuesta, conectar con la población pidiéndole su memoria sobre la ciudad del pasado y sus ideas sobre el futuro, activando así su capacidad participativa, lo que también se está diseñando en el marco del Proyecto.

En materia de difusión, no sólo las exposiciones, aunque son necesarias, sirven para divulgar el conocimiento. En la ciudad las relaciones se vertebran mediante otros circuitos, muy reacios a verse influidos por los medios habituales de expresión científica o institucional (en los casos de barrios deprimidos-marginales esto es lo frecuente).

Se le puede dar la vuelta: Tal vez seamos nosotras las que nos hemos interesado en la vida de la ciudad $y$, fijándonos en acciones del Movimiento Vecinal de Jaén, dirigidas a la recuperación de la memoria de la ciudad histórica, llevando a cabo su propia encuesta sobre el particular, hemos encontrado un objetivo para desarrollar dentro del Proyecto de Arqueología Urbana: 
* Introducir el argumento histórico en estas acciones, aportando nuestra experiencia y nuestro conocimiento sobre la ciudad del pasado.

En el reto de la difusión del Proyecto de Arqueología Urbana vemos fundamental una verdadera programación de las integraciones a realizar, y no desde la perspectiva de hitos históricos exclusivamente. La presentación de la información material (restos arqueológicos) de la ciudad del pasado, se ha de convertir en un ejercicio de diseño del presente. Elementos verdaderamente integrados en la ciudad de hoy, capaces de ser comprendidos, usados y apropiados por la sociedad actual, son en nuestra opinión la mejor defensa. Vamos a deshacer esa imagen del Patrimonio Arqueológico como algo a proteger, y vamos a extender la de un Bien Colectivo a disfrutar.

Sólo ahora se está iniciando el estudio de la viabilidad de este tipo de diseños, en los que se hace convivir lo pasado con el presente. En nuestra ciudad hay poca experiencia sobre el tema, aunque existen omisiones y algunos intentos frustados que es imprescindible analizar. Es necesario utilizar lo aprendido en otras ciudades con más experiencias, aunque conviene no tomar como referentes exclusivos los extremos, es decir, partir de la imagen de Roma (tan tópica y recurrente), nos puede alejar, más que acercar, a nuestro objetivo.

Creemos de particular riqueza extraer conclusiones de la práctica de integración de restos arqueológicos, realizada en los últimos 10 años en la Comunidad Autonoma Andaluza. Ciudades como Málaga, Córdoba o Cádiz guardan una información, a nuestro juicio imprescindible, para elaborar esos criterios generales de conservación del Patrimonio Arqueológico necesarios a la hora de diseñar cualquier proyecto de Arqueología Urbana.

En este sentido, los objetivos básicos que debe proporcionar la práctica arqueológica son conocimiento histórico, y un incremento del patrimonio. Esto implica investigación y conservación. La investigación requiere un proyecto que planteé hipótesis, centradas en la propuesta de un modelo de reconstrucción/intepretación del proceso histórico de la ciudad, mientras que la conservación requiere, para poder intervenir, que sepamos aqueIlo que se quiere conservar y proteger (SALVATIERRA, 1994).

De esta manera, ambos elementos están indisolublemente unidos, y no pueden disociarse al diseñar un proyecto de investigación sobre la ciudad, donde el primer paso a dar, sería llegar a un conocimiento previo de dicho Patrimonio, de su situación y de las condiciones de su incremento.

En el momento de la concesión de una subvención por parte de la Junta de Andalucía para el Proyecto de Arqueología Urbana en JaénI, una primera fase de acercamiento a la realidad, y el diseño de un registro sistematizado, ya habían sido iniciados tal como exponemos más arriba, por lo que uno de los objetivos de nuestro proyecto es mantener esta línea en desarrollo, porque pensamos que el modelo de registro a aplicar es algo en construcción constante y que se realimenta con las nuevas experiencias.

Junto a ello, era necesario plantear las estrategias de actuación a seguir, para la obtención de información arqueológica e inclusión de esta en el Sistema Urbano.

\section{Las distintas tipologías de intervención.}

La prospección superficial, como método no agresivo de actuación arqueológica, es el primer tipo de intervención a redefinir dentro del Proyecto de Arqueología urbana. Hay que considerar este método como la primera posibilidad de toma de contacto con la realidad de la información arqueológica, lo que será decisivo a la hora de tomar decisiones mediante el análisis de los datos.

Dos son los subtipos de prospección que hemos tenido oportunidad de ensayar y aplicar al caso concreto de la ciudad de Jaén: 
* En primer lugar la prospección de áreas urbanas consolidadas, con el objetivo básico de registrar la información actual mediante la observación de los indicadores de potencia arqueológica visibles, aplicando las siguientes técnicas:

- Comprobación de la existencia de estructuras que hayan podido modificar o destruir el substrato arqueológico (bodegas, sótanos, pozos, redes de saneamiento público o privado, etc.).

- Análisis estratigráfico murario, que aporta los datos esenciales para una determinación de la evolución de los edificios. Caracterizando los diferentes tipos de fábrica con las consiguientes deducciones de cronología.

- Reconstrucción diacrónica del trazado urbanístico mediante la observación de las alineaciones actuales de calles y evidencias de su evolución (retranqueos, invasiones de espacios públicos por inmuebles etc.)

Todo ello en relación muy directa con la información aportada por la documentación escrita.

* En segundo lugar la prospección de las zonas periféricas de la ciudad actual. La comprensión de la ciudad histórica implica el conocimiento de su entorno inmediato y de sus límites, es decir, las zonas suburbanas o rurales. Es necesario definir y caracterizar las zonas arqueológicas que engloban o rodean en diferentes momentos a la ciudad, porque su delimitación contribuye de forma notable a un aumento del conocimiento sobre nuestro sujeto de estudio. Evidentemente, la caracterización de un determinado hábitat rural dice muchas cosas sobre el núcleo ciudadano del que depende.

Se añade a esto, la urgencia impuesta desde el planeamiento urbano, actualmente en redacción. Nos referimos a áreas recalificadas como suelo urbanizable, programado y no programado, en la Revisión del Plan General de Ordenación Urbana y cuya información arqueológica está, por lo tanto, en inminente peligro de desaparecer.
La excavación, sigue siendo el tipo de intervención arqueológica que más datos aporta para la investigación histórica. En un sentido amplio, la excavación arqueológica se define como aquella actuación realizada con una metodología adecuada, cuyo fin es estudiar, documentar, conservar o simplemente comprobar, la existencia de estructuras inmuebles soterradas o unidades de estratificación de interés histórico. Desde el Proyecto de Arqueología urbana son varias las actuaciones que consideramos como tales.

* Seguimiento arqueológico, efectuado mediante la vigilancia de un profesional de los movimientos de tierra ejecutados por medios mecánicos, cuyo fin es controlar la presencia de un primer indicador de potencia arqueológica.

* Sondeo arqueológico, es decir, la práctica de un número reducido de catas, con el fin de evaluar la riqueza arqueológica de una espacio acotado de terreno.

* Excavación extensiva de aquellas áreas donde se tiene certeza de su potencialidad arqueológica.

Estas intervenciones no son excluyentes entre sí, y su aplicación parte del grado de información previa que se tiene sobre las áreas afectadas, y de la planificación de las estrategias de trabajo establecidas en el Proyecto de investigación, que a su vez, dependen de los objetivos científicos marcados y de la necesidad de racionalizar y rentabilizar los medios disponibles.

El estudio de los materiales recuperados, es otro de los tipos de intervención imprescindible para la obtención de cronologías y caracterización de las distintas culturas que han habitado la ciudad.

La metodología de registro y análisis del conjunto de materiales que hemos elaborado ya ha sido expuesta más arriba, por lo que no abundaremos más en su descripción, no obstante el trabajo se ha organizado en dos vertientes: 
* Recuperación de todos los materiales de antiguas intervenciones para su análisis global, lo que permitirá completar el conocimiento adquirido a través de los estudios parciales realizados hasta la fecha. Su inventariado y registro sistemático a partir de la ficha diseñada ha sido el primer paso en este sentido.

* Integración de la ficha de registro en el conjunto de documentación que se debe cumplimentar en cada una de las nuevas excavaciones que se han realizado desde la aprobación del proyecto.

\section{Información arqueológica y planeamiento urbanístico.}

No deja de ser curioso que dejemos para el final lo que, en teoría, debiera haber sido el principio. No obstante, es el reflejo de la realidad. La capacidad de ofrecer datos al planeamiento urbanístico, la posibilidad de introducir la información arqueológica en los planes urbanísticos, no está al alcance de muchos grupos de investigación arqueológica. En realidad, el conocimiento de las ciudades superpuestas -que cuenta con una bibliografía respetable e incluso abundante- no soluciona, salvo excepciones, cuestiones básicas tales como la normalización de los criterios de conservación del patrimonio arqueológico, que harían posible la introducción de esta información en las figuras de planeamiento y el diseño de normativa de protección específica para evitar tensiones $y$, fundamentalmente, para generar riqueza con la recuperación de la memoria del pasado en la ciudad actual.

En primer lugar, conviene establecer que la actividad planificadora es objetivamente necesaria para efectuar un control sobre la ocupación del territorio, ya sea urbano o rural. Así, cuando hablamos de Planeamiento, estamos tratando de "una actividad pública que se desarrolla en base a las necesidades y las aspiraciones del grupo social hacia el que está dirigida, con el objetivo de organizar acciones que, incidiendo sobre condiciones actuales, afecten situaciones futuras" (BRUSILOVSKY, FRANCHINI, 1992, p.19).
El argumento histórico (del que la información arqueológica es una parte) no es el único a manejar en el proceso planificador de la ciudad, pero es, a nuestro juicio, determinante, si queremos mejores ciudades, ciudades con una más alta calidad de vida. Si entendemos que la recuperación de la memoria del pasado es un recurso aprovechable, podemos diseñar modos de recuperación idóneos, evitando tensiones. Por esto parece importante que todo lo que se refiera a la ciudad esté normalizado en la figura correspondiente. Es decir, es siempre preferible que la norma a aplicar sea la misma que para el resto de las actividades ciudadanas. Bien es cierto que se puede acudir para "proteger" a leyes especiales (Patrimonio Histórico), y a veces ha sido necesario, aunque podemos cuestionarnos hasta que punto ha resultado socialmente eficaz.

En nuestra ciudad, el nacimiento de la Arqueología Urbana proviene de la aplicación de las leyes sectoriales (LPHE, LPHA) desde la Administración tutelar, la Consejería de Cultura, y en concreto en el ámbito de las Comisiones Provinciales de Patrimonio Histórico, que emiten informe vinculante sobre la concesión de licencias en las ciudades de la provincia declaradas o incoadas Bien de Interes Cultural- Conjunto Histórico.

Las primeras intervenciones arqueológicas desarrolladas en la ciudad se deben al control que, de las sustituciones de edificios en el casco histórico, efectúa la Comisión Provincial de Patrimonio Histórico. El mecanismo aplicado hasta la fecha es así de simple: todos los edificios que se sustituyen o que solicitan licencia de obras que altere el subsuelo, reciben del Ayuntamiento Licencia Provisional condicionada a informe arqueológico previo, siguiendo el Ayuntamiento a su vez la condición impuesta por la C.P.P.H. Este organismo consultivo sólo controla las licencias del Conjunto Histórico y esto sera así hasta la aprobación del Plan Especial de Protección y Reforma Interior. Todo lo que queda fuera del Conjunto, depende de la conciencia ciudadana en forma de denuncias o comunicaciones de hallazgos y de la posibilidad de ejercer vigilancia de la administración tutelar. 
El Plan General de Ordenación Urbana de Jaén-86 difícilmente podía recoger una información, la arqueológica, que en el momento de su redacción era inexistente. Un primer avance se publica en el Anuario Arqueológico Andaluz de 1987 (CASTRO, 1987), se trata en ese momento de esbozar a grandes rasgos las potencialidades de recuperación de información histórica mediante la intervención arqueológica.

Pero no es hasta 1993 cuando un equipo encabezado por una de nosotras (MCPM) puede retomar, en el marco de un proyecto de Arqueología Urbana, subvencionado por la Consejería de Cultura de la Junta de Andalucía, este primer avance de Zonificación Arqueológica, procediendo a la revisión de este trabajo en función de los resultados de las casi 80 intervenciones que se han realizado desde 1987 hasta la fecha, así como su ampliación, introduciendo el cinturón periférico recalificado como suelo urbanizable, y diseñando una normativa básica de protección: zona de protección, zona de servidumbre, zona de cautela y zona de vigilancia arqueológica. En cada una de ellas se especifica el tipo de actuación necesaria, el porcentaje de superficie a excavar y el tiempo máximo de intervención para un diagnóstico previo, así como las medidas de conservación de los restos y la difusión de sus resultados.

En la actualidad, la aprobación provisional de la Revisión del PGOU y la aprobación inicial del PEPRI, esta vez con contenidos de información arqueológica, abren perspectivas hacia fórmulas de gestión de estos recursos.

Se plantean y ya están ensayadas en otras ciudades, maneras de gestión de estas actividades:

* control de la administración tutelar (Comunidades autonomas) mediante una política de declaraciones o catalogaciones que se superpongan a la normativa urbanística de la ciudad.

* control municipal mediante gerencias de urbanismo dotadas de personal capacita- do para ejercer estas funciones, que pongan en práctica lo planificado en el plan general de la ciudad.

Estas dos fórmulas derivan en sistemas de financiación distintos, que son quizás el núcleo de las tensiones en la mayoría de los casos:

* financiación privada de las actividades a cargo del promotor de las nuevas edificaciones.

* financiación pública.

* financiación mixta

También se plantea el reto de nuevos profesionales que sepan adaptarse a esta específica forma de hacer arqueología, que tienen que trabajar en el marco del Sistema Urbano, haciendo válido el argumento de la información histórica para la ciudad del presente.

En cualquier caso, es imprescindible desde nuestro punto de vista, considerar que el tema de la Arqueología Urbana es un asunto de la ciudad actual, y que es en el marco de sus sistemas de representación política y de planificación urbana, donde se debe incluir la información arqueológica, considerar sus problemas y potencialidades, donde se deben diseñar las normativas de protección más adecuadas a cada realidad. Y todo esto, y desde el principio, con la participación ciudadana.

\section{BIBLIOGRAFÍA.}

ALCAZAR, E.M. (1994): "Propuesta metodológica para la creación de un Sistema de Información Arqueológica de la ciudad", Arqueología y Territorio Medieval, n I. Jaén, pp. $209-215$.

ARROYO-BISHOP, D.(199I): "El Sistema ArchéoDATA: Hacia la creación de un Sistema de Información Arqueológica", Aplicaciones informáticas en Arqueología, Complutum, n I. Madrid, pp. 167-174.

AZZENA, G.; TASCIO, M. (1988): "Dalla formalizzazione della metodologia di ricerca sulla città alla informatizzazione dei dati archeologici urbani", SECONDINI, P. (ed.), La Conoscenza del Territorio e dell'Ambiente. Milán, pp. 173- 187. 
AZZENA, G.(1992): "Tecnologie Cartografiche Avanzate applicate alla Topografia Antica", BERNARDI, M.(ed.), Archeologia del Paesaggio. Florencia, pp. 747-765.

BRUSILOVSKY FILER, B.; FRANCHINI,T (1992): Planeamiento Urbano. Procedimiento y Acción. Madrid.

CANO, J.(en prensa): "Intervención arqueológica de apoyo a la restauración en el Palacio de los Uribes", Anuario Arqueológico de Andalucía 1994. Sevilla.

CARMONA, J.(1994): "De la participacion ciudadana al desarrollo pasando por el Patrimonio. El caso del Parque de Miraflores", Boletín del Instituo Andaluz del Patrimonio Histórico, nº Sevilla, pp. 29-32.

CASTILLO, J.C.; CASTILLO, J.L.(1989): "Intervención de apoyo a la restauración en las Criptas de la Iglesia de $\mathrm{S}$. Juan", Anuario Arqueológico de Andalucía. Sevilla, pp. 292-304.

CASTILLO, J.C.; CASTILLO, J.L.(199|): "Nuevos datos sobre el Urbanismo del Jaén islámico: Las criptas de la Iglesia de S. Juan", Miscelánea de Estudios Árabes y Hebráicos, n 19. Sevilla.

CASTILLO, J.L.; MARIN, M.; PEREZ, M‥C.; ZAFRA, J.(en prensa): "Intervención arqueológica de urgencia en el solar situado entre las calles, Millán de Priego, Rey D. Pedro, Horno Franco y S. Andres", Anuario Arqueológico de Andalucía 1992. Sevilla.

CASTRO, M. (1987): "Zonificación Arqueológica del Suelo Urbano de la Ciudad de Jaén (avance)", Anuario Arqueológico de Andalucía. Sevilla, pp. 338-344.

HARRIS, E.C. (|99|): Principios de Estratigrafía Arqueológica. Barcelona.

JIMENEZ, Y.; CHICA, P.(en prensa): "Intervención arqueológica de urgencia en el solar de la C/ Martínez Molina, Cl Corregidores, Cl Baños de la Audiencia y C/ Doctor García Anguita", Anuario Arqueológico de Andalucía 1992. Sevilla.
LÁZARO DAMAS, Ma S.(1988): Desarrollo histórico del Casco Urbano de Jaén hasta 1600. Jaén.

PÉREZ, Ma.C.; ALCÁZAR, E.Mª. (1993): "Aproximación al urbanismo de Jaén en el siglo XI", El Baño Árabe del Naranjo y la formación del edificio los Caños. Jaén.

PÉREZ, Ma.C.; JIMÉNEZ, Y. (en prensa): "Intervención arqueológica de urgencia en el solar de la calle Martínez Molina esquina calle Los Caños", Anuario Arqueológico de Andalucía 1992. Sevilla.

SALVATIERRA, V. (1994): "Arqueología urbana: Investigación o Intervención", Patrimonio y Ciudad. Reflexión sobre centros históricos. Sevilla, pp. 7I-76.

SALVATIERRA, V. (1993): "Jaén en los siglos XIII y XIV. La formación de la ciudad cristiana", Revista del Centro de Estudios Históricos de Granada y su Reino, n 7, Segunda época. Granada, pp. 149-167.

SALVATIERRA, V.; PÉREZ, Ma.C:; CASTILLO, J.L:; ALCA ZAR, E.Ma.; CANO, J. (1993): "Formación y evolución de una ciudad islámica: Jaén", IV Congreso de Arqueología Medieval Española, Tomo II. Alicante, pp. 87-94.

SERRANO, J.L.; JIMÉNEZ, Y.; ZAFRA, J.(inédito): Aurgi: un municipio romano desde la Arqueología urbana.

ULIERTE, L. (1990): Jaén. La ciudad y su historia. Granada.

ZAFRA, J.(en prensa): "Intervención arqueológica en el solar n 2 de la Cl Borja", Anuario Arqueológico de Andalucía 1993. Sevilla.

ZAFRA, J:; CANO, J.(en prensa): "Intervención arqueológica de urgencia en el solar n 9 de la C/ Las Huertas", Anuario Arqueológico de Andalucía 1994. Sevilla.

W.AA. (1992) : La Carta de Riesgo. Sevilla.

W.AA. (1993): El Baño Árabe del Naranjo y la formación del edificio los Caños. Jaén. 

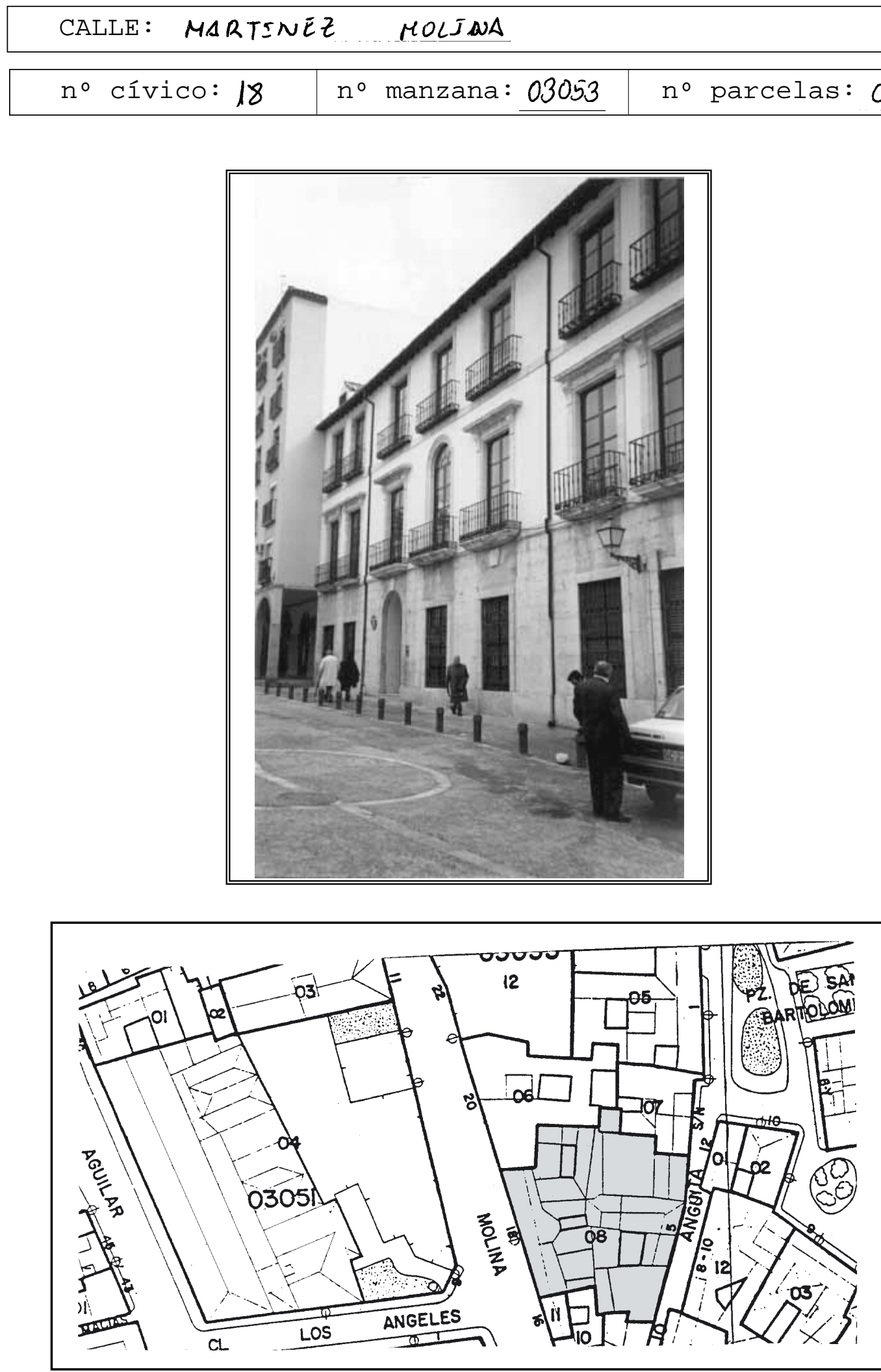

REFERENCIA CARTOGRÁFICA. ESCALA:

Fig. I 


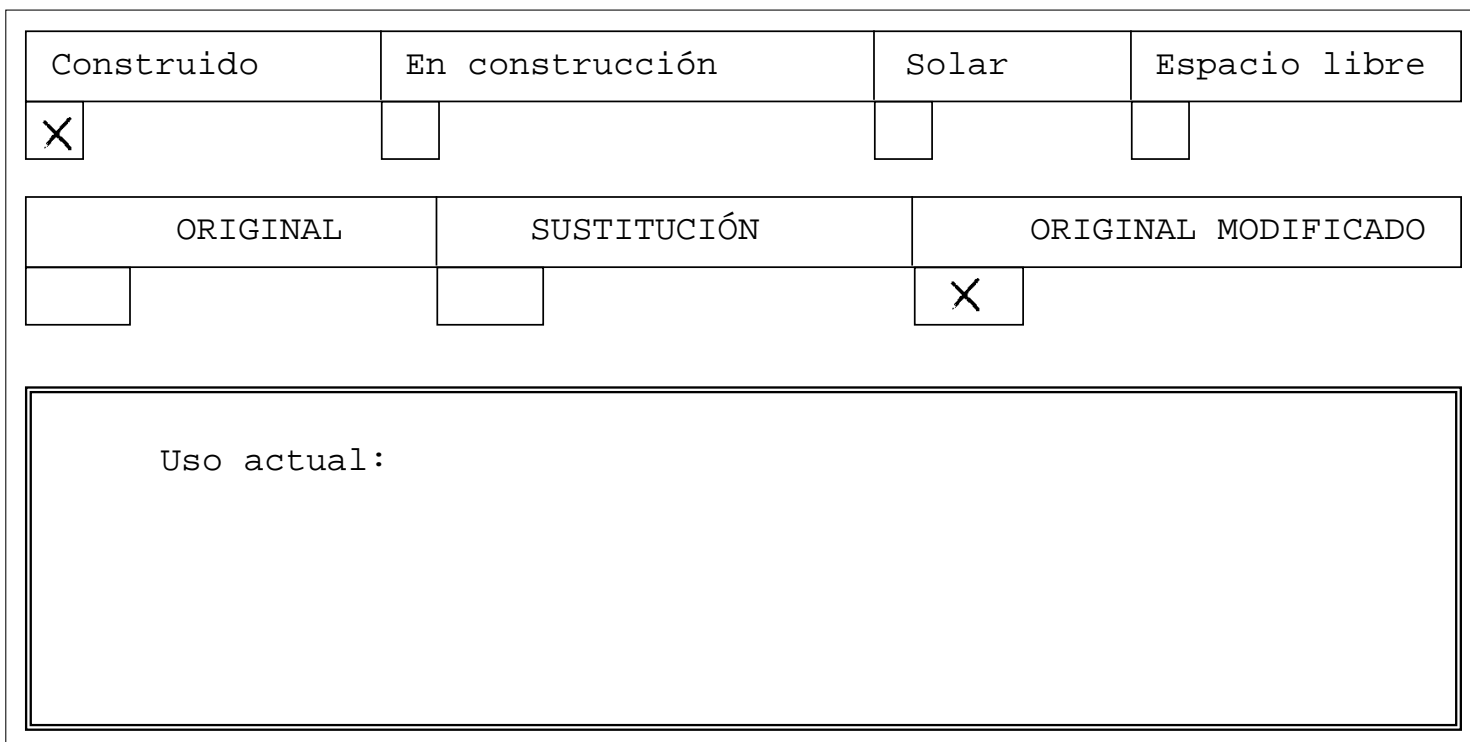

Elementos que alteren el subsuelo:

Estado de conservación:

MODIFICACIONES :

\begin{tabular}{|c|c|c|}
\hline DATOS ARQUEOLÓGICOS & SI & \$X \\
\hline DATOS HISTÓRICOS & NO \\
\hline EXPEDIENTE CPHA: $\mathbf{9 4 / 9 1}$ & \\
\hline
\end{tabular}

DOCUMENTACIÓN GRÁFICA:

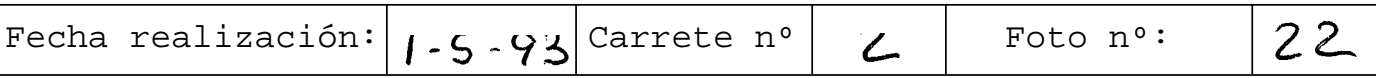

Responsables de prospección:

Fig. 2 


\section{FICHA DE INFORMACION AROUEOLOGICA (I)}

CALLE y NUMERO:

FECHA:

CAUSAS DE LA INTERVENCION:

TIPO DE ACTIVIDAD:

RESPONSABLES

\begin{tabular}{|l|c|c|}
\hline \multirow{2}{*}{ DIAGNOSTICO } & Positivo & Causas diagnostico negativo: \\
\cline { 2 - 2 } & Negativo & \\
\hline
\end{tabular}

\begin{tabular}{|l|l|}
\hline NUMERO DE SONDEOS & PORCENTAJE DE SUPERFICIE EXCAVADA \\
\hline
\end{tabular}

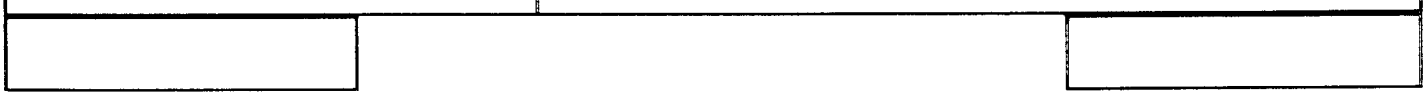

\begin{tabular}{|l|c|l|l|}
\hline \multicolumn{3}{|c|}{ PROFUNDIDAD BASE GEOLOGICA } & \\
\hline \multirow{3}{*}{ MODIFICADA } & SI & Tipo de modificación: \\
\cline { 2 - 2 } & NO & \\
\hline
\end{tabular}

FASES HISTORICAS EXISTENTES EN EL SOLAR

\begin{tabular}{|c|c|c|c|c|c|}
\hline \multirow{2}{*}{ COBRE } & SI & \multirow[t]{2}{*}{ Número } & \multirow{2}{*}{ BRONCE } & $\mathrm{SI}$ & \multirow[t]{2}{*}{ Número } \\
\hline & NO & & & NO & \\
\hline \multirow{2}{*}{ IBERICO } & $\mathrm{SI}$ & \multirow[t]{2}{*}{ Número } & \multirow{2}{*}{ ROMANO } & SI & \multirow[t]{2}{*}{ Número } \\
\hline & NO & & & No & \\
\hline \multirow{2}{*}{ VISIG. } & SI & \multirow[t]{2}{*}{ Nůmero } & \multirow{2}{*}{ MUSULM. } & SI & \multirow[t]{2}{*}{ Número } \\
\hline & NO & & & NO & \\
\hline \multirow{2}{*}{ CRIST. } & $\mathrm{SI}$ & \multirow[t]{2}{*}{ Número } & \multirow{2}{*}{ MODER. } & SI & \multirow[t]{2}{*}{ Número } \\
\hline & NO & & & NO & \\
\hline \multirow{2}{*}{ COMPT. } & SI & \multirow[t]{2}{*}{ Número } & & & \\
\hline & NO & & & & \\
\hline
\end{tabular}

Fig. 3 


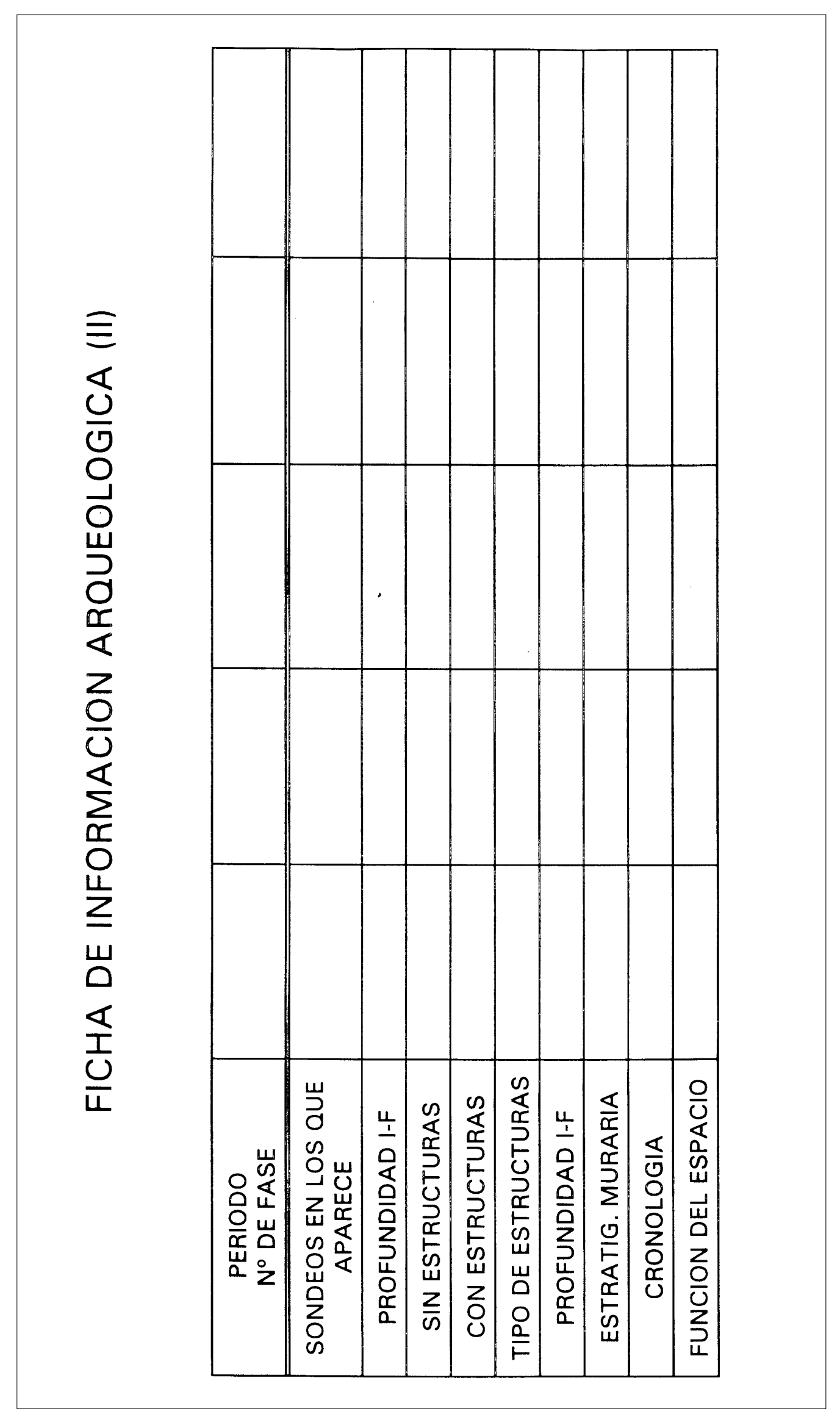

Fig. 4 


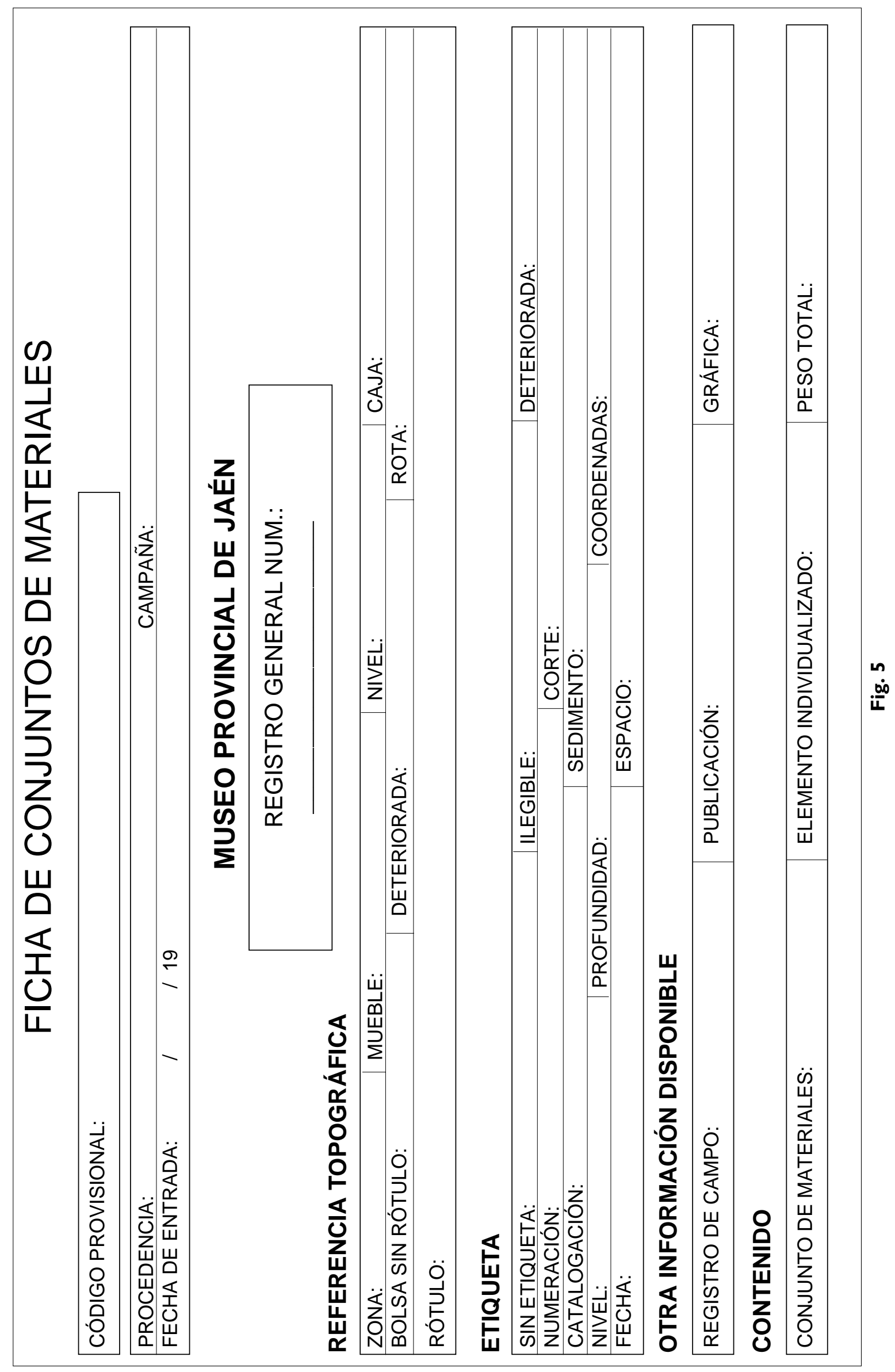




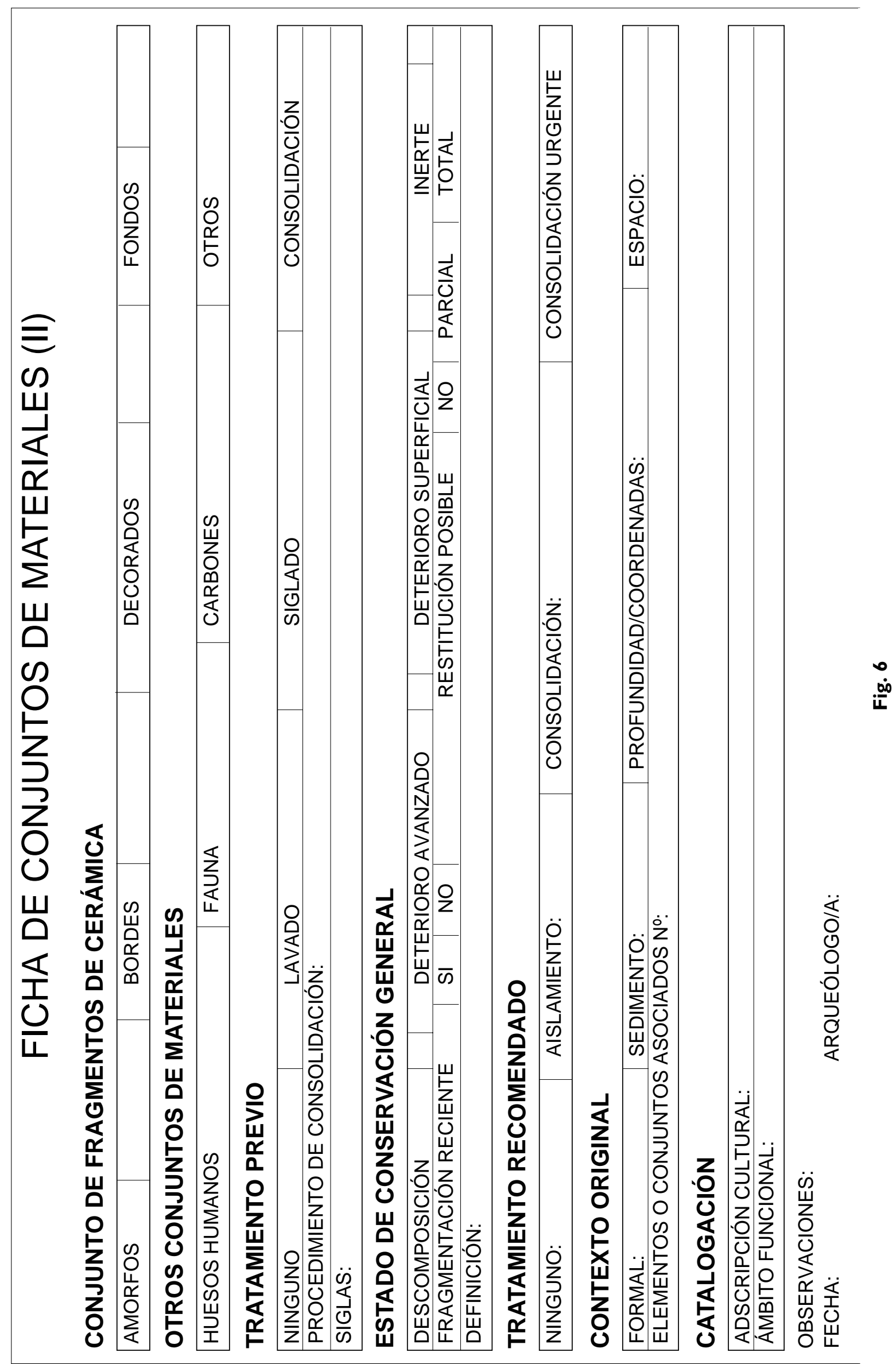


FICHA DE ESTUDIO DE MATERIALES

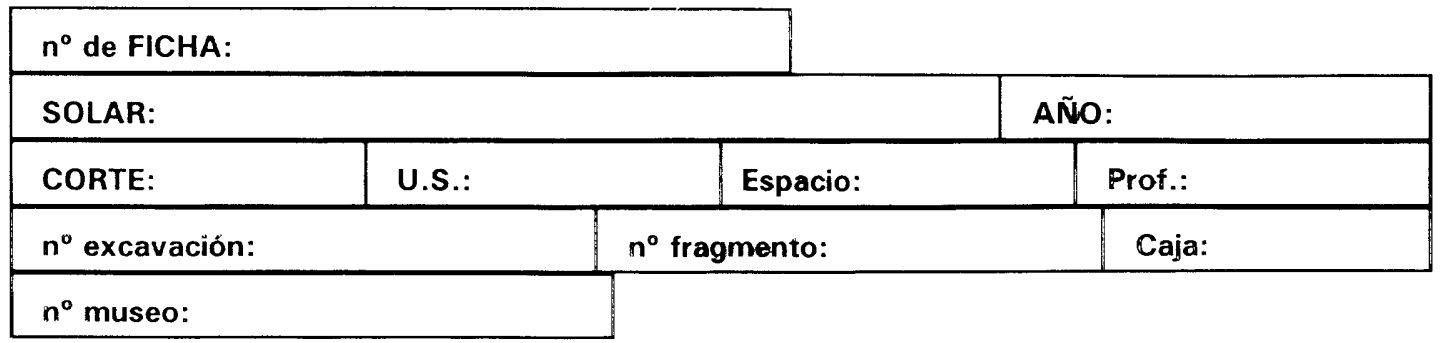

\begin{tabular}{|c|c|c|}
\hline \multicolumn{3}{|c|}{ TECNICA DE ELABORACION } \\
\hline MANO & TORNO & TORNETA \\
\hline
\end{tabular}

\begin{tabular}{|l|l|}
\hline \multirow{2}{*}{ CATEGORIA } & INDIGENA: \\
\cline { 2 - 2 } & IMPORTACION: \\
\hline
\end{tabular}

\begin{tabular}{|c||c|c|c|c|}
\hline $\begin{array}{c}\text { FORMA } \\
\text { FRAGMENTO }\end{array}$ & BORDE & FONDO & ASA & MAMELON \\
\cline { 2 - 5 } & GALBO & PATAS & CARENA & OTROS \\
\hline Descripción: & & & & \\
\hline
\end{tabular}

\begin{tabular}{|l||c|c|c|c|c|}
\hline TIPO DE COCCION & \multicolumn{2}{|c|}{ REDUCTORA } & \multicolumn{2}{c|}{ OXIDANTE } & \multicolumn{2}{c|}{ MIXTA } \\
\hline TAMAÑO DESGRAS. & GRUESO & MEDIO & FINO & MINERAL \\
\hline TRATAMIENTO DE SUPERFICIE:
\end{tabular}

\begin{tabular}{|c|c|c|c|c|}
\hline \multirow{2}{*}{ DECORACION } & SI & \multirow[t]{2}{*}{ Localización: } & & \\
\hline & No & & & \\
\hline \multirow[t]{2}{*}{ TIPO DECORAC. } & PINTADA & VIDRIADA & INCISA & EXCISA \\
\hline & ESTAMP. & BOQUIQUE & ESGRAFIADA & ENGOBE \\
\hline \multicolumn{5}{|l|}{ OTROS: } \\
\hline Descripción: & & & & \\
\hline
\end{tabular}

\section{FUNCIONALIDAD:}

PERIODO:

OBSERVACIONES:

ANALISIS QUIMICO:

MUESTRA DE PASTA:

Fig. 7 


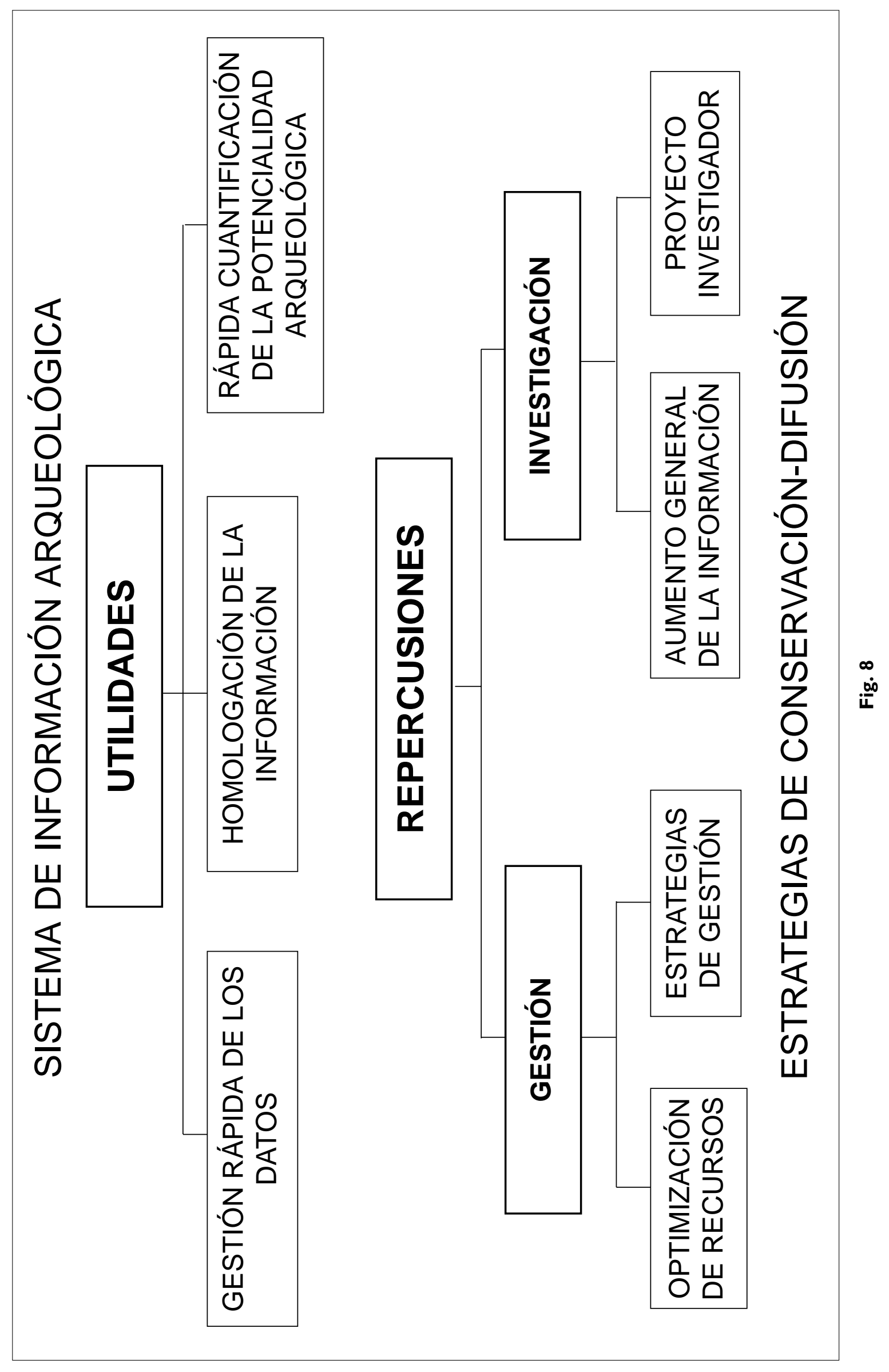

